\title{
EFEITO DO PLANTIO DIRETO NO CONTROLE DE TIRIRICA (Cyperus rotundus L.) E OUTRAS PLANTAS DANINHAS NA CULTURA DO MILHO
}

\author{
CORDEIRO, L. A. M. ${ }^{1}$;REIS, M. S. ${ }^{2}$; AGNES, E. L. ${ }^{3}$; CECON, P.R. ${ }^{3}$ \\ 1Eng.-Agrônomo, Doutor pelo Departamento de Fitotecnia da Universidade Federal de Viçosa, ex-Bolsista do \\ CNPq, Paracatu, MG, 38600-000. \\ 2Professor do Departamento de Fitotecnia da Universidade Federal de Viçosa, Bolsista do CNPq, Viçosa, MG, \\ 36571-000. \\ Professor do Departamento de Fitotecnia da Universidade Federal de Viçosa, Viçosa, MG, 36571-000.
}

RESUMO: Objetivou-se neste trabalho avaliar a dinâmica populacional de tiririca (Cyperus rotundus L.) e de outras espécies de plantas daninhas na cultura do milho (Zea mays L.) cultivado para grão e para silagem, sob plantio direto e convencional. No primeiro ano, cultivou-se o milho em área total, sendo metade da área sob plantio direto e a outra metade sob preparo convencional. Posteriormente, dividiu-se cada área em duas partes: uma para produzir milho para grão e outra para produzir milho para silagem. Foram avaliadas: a) plantas daninhas antes da dessecação e/ou preparo do solo e após a colheita do milho; e, b) controle de plantas daninhas após a aplicação dos herbicidas em pós-emergência no cultivo do milho e do feijão. Concluiu-se que: o tipo de manejo do solo influenciou o controle de $C$. rotundus $L$., sendo superior nas áreas onde fez o plantio direto, independentemente se para produção de milho para grão ou para silagem. Observou-se aumento do número de plantas de $C$. rotundus $L$. nos tratamentos sob preparo convencional e milho para silagem. Quanto às demais espécies de plantas daninhas, estas não foram influenciadas pelo tipo de manejo do solo e a finalidade de cultivo de milho, exceto a $S$. niveum Kuntze, que ocorreu somente nos tratamentos sob milho silagem.

Palavras-chave: Plantio direto; controle de plantas daninhas; tiririca; milho.

\section{NO-TILLAGE EFFECT IN YELLOW NUTSEDGE (Cyperus rotundus L.) AND OTHER WEED SPECIES CONTROL AT MAIZE CROP}

\begin{abstract}
It was aimed at in this work to evaluate the population dynamics of yellow nutsedge (Cyperus rotundus L.) and of other species of weeds at maize (Zea mays L.) crop also cultivated for grain and for silage, under no-tillage and conventional tillage of the soil conditions. In the first year, the maize was cultivated in total area, being half of the area in no-tillage and the other half in conventional tillage. Later each area was splitted in two plots: one to produce maize for grain and other to produce maize for silage. They were appraised: a) weed plants before the desiccation and/or the soil tillage and after the crop of the maize and bean; b) weed control after the application of the herbicides in post-emergency at the maize. It was ended that: the type of management of the soil influence $C$. rotundus $L$. control that was observed independently in the areas where it was made the no-tillage, whether maize for grain or silage. There was no increase of $C$. rotundus $L$. infestation at conventional tillage. Infestation of the other weeds species was not influenced by the type of the soil management or maize cultivation system, except the lyon velvet bean (Stizolobium niveum Kuntze), that had infestation at maize for silage.
\end{abstract}

Key-words: No-tillage; weed control; yellow nutsedge; maize. 


\section{INTRODUÇ̃̃O}

A tiririca (Cyperus rotundus L.) é uma das mais importantes espécies de planta daninha do mundo devido a sua rápida reprodução, e disseminação aliada a dificuldade de seu controle. A movimentação do solo no sistema convencional de manejo é a principal forma de disseminação desta espécie em todo o mundo. Isto ocorre porque, com o revolvimento do solo pelos implementos de discos ou de hastes, ocorre a fragmentação e deslocamento dos tubérculos da planta os quais originam inúmeras plântulas a cada operação de preparo. Como é uma espécie altamente competitiva por água, nutrientes e também podendo liberar substâncias alelopáticas no solo, esta é responsável por grandes perdas de produtividade em diversas culturas (Deuber, 1992; Beltrão \& Azevedo, 1994).

Com a adoção do plantio direto, sem revolvimento do solo e a manutenção de cobertura vegetal do solo (viva ou morta), verifica-se alteração na dinâmica infestação de plantas daninhas, via de regra, com diminuição de infestação (Rodrigues, 1985; Almeida, 1991). No caso da C. rotundus L. no plantio direto, não ocorre a fragmentação e o deslocamento de tubérculos no solo, reduzindo a multiplicação e disseminação desta espécie. Bom nível de controle de $C$. rotundus $\mathrm{L}$. foi observado por Seguy et al. (1999), utilizando o plantio direto, sem, contudo, atingir a erradicação da espécie, enquanto no sistema convencional ocorreu reinfestação.

O milho é uma cultura muito importante tanto em grandes como em pequenas propriedades, sendo nestas utilizado para produção de grãos e silagem. Neste trabalho objetivou-se estudar os efeitos do plantio direto no manejo e controle de $C$. rotundus $\mathrm{L}$. e outras espécies de plantas daninhas no milho cultivado para grãos e para silagem.

\section{MATERIAL E MÉTODOS}

Este trabalho foi conduzido no ano agrícola de 1998, na Área Experimental do Departamento de Fitotecnia da Universidade Federal de Viçosa, em solo argiloso contendo alta infestação de tiririca (Cyperus rotundus L.) e mucuna-branca (Stizolobium niveum Kuntze).

O experimento foi implantado segundo um esquema de parcelas subdivididas, tanto em parcelas nas parcelas de manejo do solo (plantio direto e preparo convencional) como nas subparcelas de sistemas de cultivo de milho (milho para grão e milho para silagem), no delineamento de blocos casualizados com quatro repetições. Desta forma, as parcelas foram compostas por dois sistemas de manejo do solo, plantio direto (PD) e preparo convencional (PC), e as subparcelas por dois sistemas de cultivo de milho, milho para grão (MG) e milho para silagem (MS) com quatro repetições.

Os resultados obtidos neste trabalho apresentam-se divididos em duas fases. $\mathrm{Na}$ primeira fase as espécies de plantas daninhas foram identificadas e quantificadas, e os dados destas avaliações foram submetidos à estatística descritiva ou ao Teste $\mathrm{t}$ para comparação de médias. Na segunda fase, os resultados relativos às características estudadas após a colheita do milho foram analisadas utilizando-se o programa SAEG 8.0 - Sistema para Análise Estatísticas.

Para quantificar a infestação de plantas daninhas fez-se, 16 dias antes do início do experimento e antes da dessecação, uma avaliação que teve como objetivo 
identificá-las e quantificá-las. Para esta avaliação foram realizadas 48 amostras ao acaso em diferentes pontos da área, utilizando-se quadrado metálico $(0,5 \times 0,5 \mathrm{~m})$.

Para a implantação da cultura do milho foi realizada a dessecação química em área total das plantas daninhas (C. rotundus L. e $S$. niveum Kuntze), dez dias antes da semeadura, utilizando em mistura no tanque os herbicidas glyphosate (concentração $360 \mathrm{~g} / \mathrm{L}$ e dose 3,0 L/ha) e 2,4-D amina (concentração $670 \mathrm{~g} / \mathrm{L}$ e dose $1,0 \mathrm{~L} / \mathrm{ha})$.

O preparo primário do solo nas parcelas sob preparo convencional foi realizado por meio de uma aração profunda $(30 \mathrm{~cm})$ com arado reversível de três discos, e posteriormente, duas gradagens com grade de discos tipo "off-set".

$\mathrm{Na}$ semeadura do milho, utilizou-se o híbrido triplo precoce cv. 'AG-1051'. Esta operação foi realizada em 07/11/98, com semeadora-adubadora, específica para plantio direto, modelo SEMEATO SHM-11/13, com espaçamento entre linhas de 1,0 $\mathrm{m}$ e regulada para obtenção de 70.000 mil plantas por hectare. Durante o experimento foi feita irrigação por aspersão sempre que necessário.

Posteriormente, durante a cultura do milho, foi realizada identificação e quantificação da população de plantas daninhas (número de plantas $/ \mathrm{m}^{2}$ ), oriundas de reinfestação das plantas daninhas presentes na área, aos 18 dias após a emergência do milho, porém, antes da aplicação do herbicida em pós-emergência.

O controle de plantas daninhas na cultura do milho foi feito em pós-emergência aos 17 dias após a emergência com a mistura de nicosulfuron (concentração $40 \mathrm{~g} / \mathrm{L}$ e dose 1,0 L/ha) e atrazine (concentração $500 \mathrm{~g} / \mathrm{L}$ e dose 3,0 L/ha).

A avaliação da eficiência de controle das plantas daninhas pelo tratamento aplicado em pós-emergência foi realizada aos 16 dias após a aplicação, atribuindose as notas de $0 \%$ (zero porcento) para ausência de controle a $100 \%$ (cem porcento) controle total da espécie na cultura do milho.

\section{RESULTADOS E DISCUSSÃO}

As médias observadas com seus respectivos desvios-padrão para a densidade populacional das plantas daninhas infestantes e predominantes na área experimental antes do início do experimento, encontram-se no Quadro 1.

Quadro 1. Espécies de plantas daninhas infestantes da área experimental e densidade populacional $\left(\mathrm{n} \% / \mathrm{m}^{2}\right)$ antes da implantação do experimento a campo, Viçosa-MG, 1998.

\begin{tabular}{lc}
\hline \multicolumn{1}{c}{ Espécies infestantes } & Densidade populacional ( $\overline{\mathrm{X}} \square \mathrm{s})$ \\
\hline Cyperus rotundus L. & $721 \square 171$ \\
Stizolobium niveum Kuntze & $3,62 \square 2$ \\
\hline${ }^{*}$ Média mais desvio-padrão &
\end{tabular}

Como se pode observar, a $C$. rotundus $L$. era a planta daninha dominante, com alta população inicial, sendo que a $S$. niveum Kuntze ocorria com menor freqüência (em reboleiras), sendo considerada planta daninha nesta área devido ao manejo inadequado ao longo dos últimos anos.

Após a dessecação das espécies presentes na área, utilizando-se a mistura de glyphosate $+2,4-D$, verificou-se a reinfestação da área com $C$. rotundus L. e $S$. niveum Kuntze, entre outras, sendo estas espécies identificadas e quantificadas nas 
parcelas sob plantio direto e sob preparo convencional cultivadas com milho (Quadro 2).

A aplicação de glyphosate + 2,4-D na operação de manejo proporcionou bom controle da população inicial de plantas daninhas, verificando-se, contudo, reinfestação de $C$. rotundus $L$. Este resultado está de acordo com aqueles obtidos por Almeida (1991), o qual afirmou serem necessárias várias aplicações seqüenciais para efetuar o controle desta espécie com herbicidas sistêmicos. Também Rodrigues \& Almeida (1998) destacaram a importância de reaplicações de glyphosate para controle efetivo de $C$. rotundus L. visando eliminar brotações provenientes de órgãos não atingidos.

A infestação da área experimental com plantas daninhas pertencentes às famílias das gramíneas e das dicotiledôneas a exceção de $A$. deflexus L. e $O$. latifolia, foi muito baixa em decorrência da alta dominância com $C$. rotundus $L$.

Quadro 2. Espécies infestantes, família, densidade populacional $\mathbb{1}^{1 /}\left(n^{\circ} / m^{2}\right)$ e desviopadrão (s) das principais espécies de plantas daninhas presentes nas parcelas submetidas ao plantio direto e preparo convencional após a emergência do milho, Viçosa-MG, 1998.

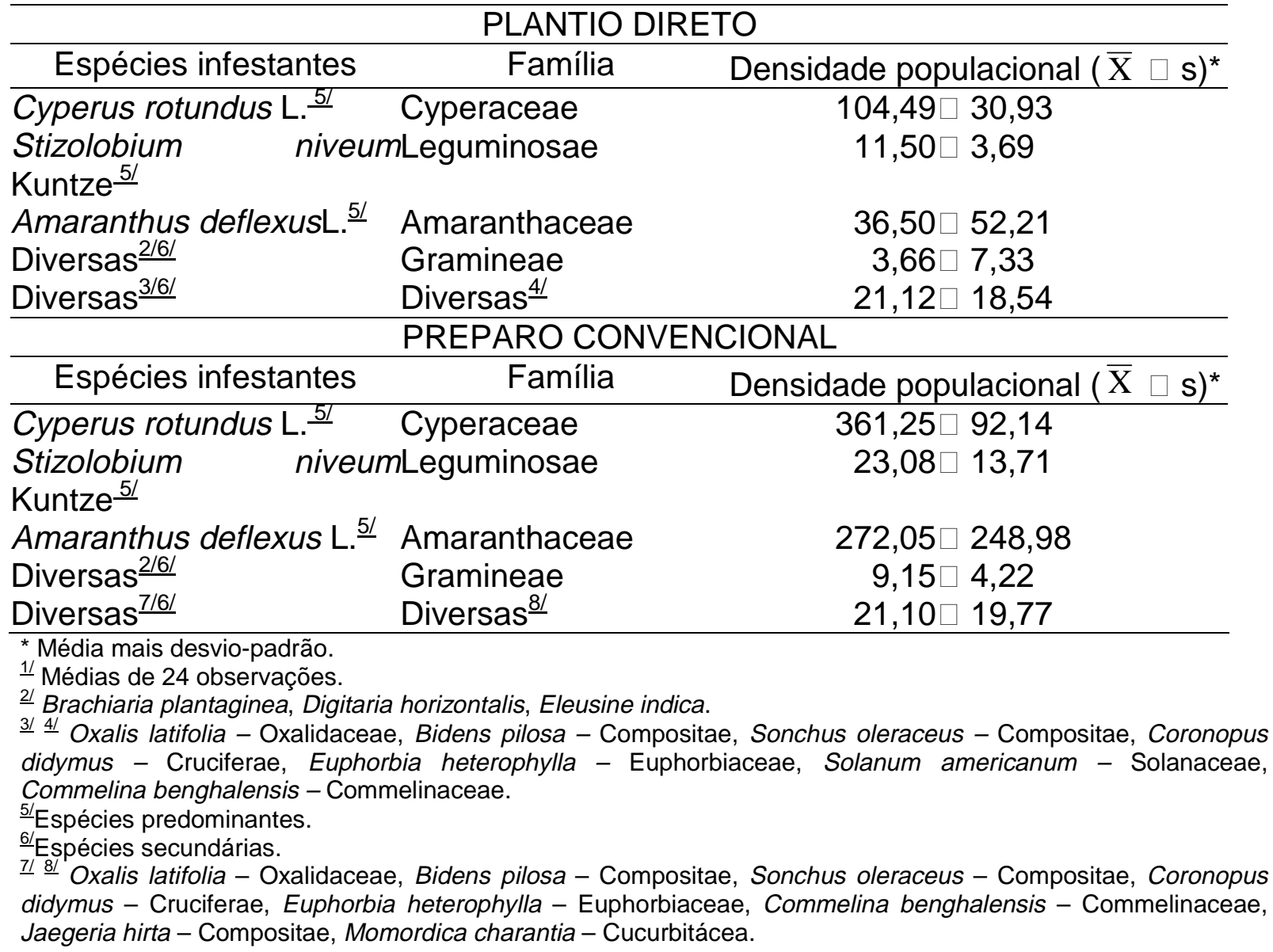

Pelos valores apresentados no Quadro 2, percebe-se que a população de $C$. rotundus $\mathrm{L}$. nos tratamentos sob preparo convencional foi três vezes e meia a observada sob plantio direto. Isto ocorreu, possivelmente, devido ao revolvimento do 
solo com arado e grade naquele sistema de manejo, o qual contribuiu na partição de tubérculos e rizomas em várias partes, originando assim novas manifestações epígeas daquela espécie. Além disso, a ausência de cobertura morta proporcionou menor impedimento físico para a emergência de plântulas.

Resultados semelhantes a estes foram observados por Forster \& Cerdeira (1993), os quais afirmam que a C. rotundus L. é altamente beneficiada pelos cultivos intensivos do solo, pelo emprego de implementos e máquinas de preparo do solo, o que favorece sua multiplicação e dispersão, bem como aprofundamento das suas estruturas reprodutivas.

Nota-se também que a população de $S$. niveum Kuntze também foi duas vezes mais alta no preparo convencional do que no plantio direto. Da mesma forma, a população de $A$. deflexus L. e de gramíneas foi numericamente mais alta no preparo convencional do que no plantio direto.

Gazziero \& Souza (1993) observaram que algumas espécies, principalmente, as anuais tendem a reduzir a infestação em áreas sob plantio direto. Também Voll (1987) observou a redução de infestação de Amaranthus sp. em sistema de plantio direto, quando comparado com preparo convencional.

Quanto a eficiência dos herbicidas (nicosulfuron + atrazine) aplicados em pósemergência do milho (Quadro 3) verifica-se alta eficiência deste tratamento (controle $\square 95 \%$ ) para todas as espécies infestantes da área com exceção de $C$. rotundus $L$. que teve apenas controle regular (80\%) e de S. niveum Kuntze (70-90\%).

Quadro 3. Eficiência da mistura de herbicidas em pós-emergência (nicosulfuron + atrazine) no controle de plantas daninhas na cultura do milho aos 16 dias após a aplicação (D.A.A.) em plantio direto e preparo convencional, em Viçosa-MG, 1998.

\begin{tabular}{lcc}
\hline Espécies infestantes & \multicolumn{2}{c}{ "'Controle (\%) } \\
\cline { 2 - 3 } & Plantio Direto & Preparo Convencional \\
\hline Cyperus rotundus & 80 & 80 \\
Stizolobium niveum & 70 & 90 \\
Amaranthus deflexus & 100 & 100 \\
Brachiaria plantaginea & 95 & 95 \\
Eleusine indica & 100 & 100 \\
Digitaria horizontalis & 100 & 100 \\
Sonchus oleraceus & 100 & 100 \\
Coronopus didymus & 100 & 100 \\
Solanum americanum & 100 & $*$ \\
Oxalis latifolia & 100 & 100 \\
Bidens pilosa & 100 & 100 \\
Commelina benghalensis & 100 & 100 \\
Euphorbia heterophylla & 100 & 100 \\
Ageratum conyzoides & 100 & 100 \\
Jaegeria hirta & $*$ & 100 \\
Momordica charantia & $*$ & 100
\end{tabular}

11Eficiência de controle - 0\% (ausência de controle) a 100\% (controle total)

* Espécie não observada 
Apesar da eficiência de controle da parte aérea de $C$. rotundus $\mathrm{L}$. pelos herbicidas aplicados (nicosulfuron + atrazine) ter sido similar em ambos os sistemas de manejo do solo ( $80 \%$ de controle) verificou-se alta reinfestação da área de preparo convencional. Isto ocasionou porque os produtos utilizados não exercem atividade herbicida capaz de eliminar as rebrotas dos tubérculos. Como existia maior número na área do manejo sob preparo convencional, isto proporcionou maior reinfestação.

Destaca-se também que no sistema plantio direto houve efeito físico da cobertura morta e da não partição de tubérculos de $C$. rotundus $L$., uma vez que não ocorreu preparo mecânico do solo. Ao contrário, no preparo convencional a intensidade de rebrota desta espécie foi maior, provavelmente, devido à partição dos tubérculos e rizomas e ausência de cobertura vegetal na superfície do solo, além de grande variação térmica do solo que favorece a brotação de $C$. rotundus $L$.

No caso da S. niveum Kuntze verificou-se, aproximadamente, $70 \%$ de controle na área de plantio direto. Nesta área, apesar de baixa população inicial, verificou-se elevada taxa de germinação devido à manutenção de grande quantidade de sementes viáveis na superfície do solo logo após a aplicação dos herbicidas dessecantes. Ao contrário, no preparo convencional, com o enterrio de sementes dessa espécie pelo preparo primário do solo através da aração profunda, ocorreu, inicialmente, diminuição da população de S. niveum Kuntze. Assim sendo, neste sistema de manejo do solo o controle desta espécie foi proporcionado pelo enterrio das sementes. No plantio direto, por sua vez, o controle foi menor, uma vez que ocorreu germinação escalonada das sementes presentes na superfície do terreno, pois, as sementes desta espécie possuem diferentes graus de dormência.

A mistura de herbicidas em pós-emergência (nicosulfuron + atrazine) apresentou $100 \%$ de controle para todas as espécies latifoliadas presentes na área, e também para as gramíneas, exceto para B. plantaginea, onde observou-se $95 \%$ de controle. Isto pode ser explicado, pois, recomenda-se aplicar o nicosulfuron para o controle efetivo desta espécie quando está no estádio de até dois perfilhos. Condições estas não observadas neste trabalho, quando foi realizada a aplicação do produto, no estádio de quatro perfilhos. Segundo Lorenzi (2000), a B. plantaginea possui susceptibilidade alta ao nicosulfuron e média ao atrazine, quando aplicado em pós-emergência inicial.

Os resultados das análises de variância para o número de plantas daninhas observadas na área experimental após a colheita da cultura do milho, estão apresentadas no Quadro 4. Por não apresentar as condições de validade da análise de variância os dados obtidos para o número de plantas de $A$. deflexus L. foram submetidos à estatística descritiva, e encontram-se no Quadro 5.

Quadro 4. Resumo da análise de variância dos dados do efeito dos tratamentos ( $\mathrm{P}$ tipos de manejo do solo e $\mathrm{M}$ - tipos de cultivo de milho) sobre o número de plantas daninhas $\left(\mathrm{n} \% / \mathrm{m}^{2}\right)$ das espécies predominantes e secundárias após a colheita da cultura do milho, em Viçosa-MG, 1999. 


\begin{tabular}{lccccc}
\hline \multicolumn{1}{c}{ F.V. } & GL & \multicolumn{4}{c}{ Quadrados Médios } \\
\cline { 4 - 7 } & & C. rotundus L. & ${ }^{1}$ S. niveum Kuntze & Gramíneas & Latifoliadas \\
\hline Bloco & 3 & 28529,26 & 0,4766 & 4,1843 & 570,9454 \\
Preparo & 1 & $474145,9^{* *}$ & $0,7575 n . s$. & $0,2805 n . s$. & $333,0625 n . s$. \\
Resíduo (a) & 3 & 25906,25 & 0,2319 & 6,3162 & 804,6475 \\
Milho & 1 & $1019600,00^{\star *}$ & $1,1819 n . s$. & $37,9764 n . s$. & 18,06250 n.s. \\
M x P & 1 & $46189,53 n . s$. & $1,6853^{*}$ & 10,0330 n.s. & $158,3822 n . s$. \\
Resíduo (b) & 6 & 23578,85 & 0,2616 & 9,8795 & 616,0433 \\
\hline C.V. (\%) Subparc. & 37,10 & 18,21 & 123,78 & 45,38 \\
\hline C.V. (\%) Parcela & 38,89 & 17,15 & 98,96 & 51,87 \\
\hline
\end{tabular}

${ }^{*} \mathrm{~F}$ significativo a $5 \%$ de probabilidade. ${ }^{* *} \mathrm{~F}$ significativo a $1 \%$ de probabilidade. n.s. não-significativo

$1 /$ Dados transformados em $\sqrt{\mathrm{x}}$

Ocorreram diferenças significativas entre os tratamentos para o número de plantas de $C$. rotundus L., com relação aos tipos de manejo de solo e de cultivo de milho (Quadro 4), mas não entre a interação destes fatores. Os fatores agiram independentemente, sendo que um fator não influenciou o outro.

Portanto, como pode se observar no Quadro 6, a população de C. rotundus L. foi maior no preparo convencional em relação ao plantio direto, e maior no milho para silagem do que no milho para grão, isoladamente, ou seja, sem que a combinação de um dos fatores indique modificação do outro. O número de plantas daninhas de $C$. rotundus $L$. nos tratamentos sob plantio direto foram inferiores aos observados na área com preparo convencional. Nos tratamentos de milho para grão este número de plantas daninhas de $C$. rotundus $\mathrm{L}$. por metro quadrado foi ainda menor quando comparado ao milho para silagem.

Quadro 5. Média $(\bar{X})$ e desvio-padrão (s) do número de plantas daninhas $\left(n^{\circ} / m^{2}\right)$ de A. deflexus L. após a colheita da cultura do milho, em Viçosa-MG, 1999.

\begin{tabular}{lrl}
\hline Tratamentos avaliados & $\overline{\mathrm{X}} \square \mathrm{s}$ \\
\hline Plantio Direto Milho para Grão (PDMG) & $1,50 \square$ & 3,00 \\
Plantio Direto Milho para Silagem (PDMS) & $52,30 \square 50,62$ \\
Preparo Convencional Milho para Grão (PCMG) & $0,00 \square 0,00$ \\
Preparo Convencional Milho para Silagem (PCMS) & $4,00 \square 4,61$ \\
\hline Média Total & $14,45 \square 32,09$ \\
\hline
\end{tabular}

Quadro 6. Valores médios do número de plantas daninhas $\left(\mathrm{n} / \mathrm{m}^{2}\right)$ de $C$. rotundus $\mathrm{L}$. após a colheita da cultura do milho, em Viçosa-MG, 1999.

\begin{tabular}{lc}
\hline Tratamentos avaliados & $\begin{array}{c}\text { Número de plantas daninhas } \\
\left(\mathrm{n} / \mathrm{m}^{2}\right)\end{array}$ \\
\hline Plantio Direto Milho para Grão (PDMG) & 42,99 \\
Plantio Direto Milho para Silagem (PDMS) & 440,16 \\
Preparo Convencional Milho para Grão (PCMG) & 279,83 \\
Preparo Convencional Milho para Silagem (PCMS) & 892,16 \\
\hline Média Total & 413,78 \\
\hline
\end{tabular}


Isto ocorreu porque o preparo do solo favorece a multiplicação vegetativa de $C$. rotundus L. (Forster \& Cerdeira, 1993). Desta forma, o plantio direto reduz esta possibilidade, por sua característica essencial da ausência de preparo. $E$ ainda, a $C$. rotundus L. consegue produzir maior volume de biomassa quando não sofre sombreamento, por ser sensível a este (Jordan-Molero \& Stoller, 1978; Patterson, 1982; Patterson, 1985). Neste sentido, nos tratamentos milho para silagem, em que se retirou a cobertura vegetal do solo no momento da ensilagem, ocorreu maior exposição das plantas de $C$. rotundus $\mathrm{L}$. à luz com aumento das condições de sobrevivência desta espécie.

Entretanto, o tratamento PDMG foi o que proporcionou menor valor do número de plantas de $C$. rotundus L., dez vezes menor do que o PDMS. Mas, no tratamento sob preparo convencional (PCMG) a população de $C$. rotundus $\mathrm{L}$. menor do que 0 tratamento sob plantio direto e milho para silagem (PDMS). O maior número de plantas de $C$. rotundus $L$. detectado no tratamento PCMS, pode ser explicado porque, como foi relatado anteriormente, a espécie favorece-se com as operações de preparo do solo (para reprodução de tubérculos e rizomas) e com a ausência de barreira física (Quadro 6).

Nesta fase do experimento, não ocorreram ainda condições suficientes para a verificação de efeitos da interação entre manejo do solo e cultivo do milho, pois, os tratamentos estavam em início de composição na área experimental. Além disso, o efeito de cobertura do solo somente será observado, possivelmente, na cultura subseqüente, com a manutenção da resteva de milho na superfície do solo. Entretanto, o fato de não revolver o solo nas parcelas sob plantio direto já proporcionou significativa redução populacional de plantas daninhas, de uma maneira geral.

Não houve diferenças significativas entre os tratamentos para o número de plantas de $S$. niveum Kuntze, de espécies gramíneas e de espécies latifoliadas, com relação aos tipos de manejo de solo e de cultivo de milho, mas houve diferença na interação entre os fatores para o número de plantas daquela espécie (Quadro 7).

Quadro 7. Número médio de plantas daninhas $\left(\mathrm{n} \% \mathrm{~m}^{2}\right)$ de $S$. niveum Kuntze após a colheita da cultura do milho, em Viçosa-MG, 1999.

\begin{tabular}{lcc}
\hline \multicolumn{1}{c}{ Cultivo de Milho } & \multicolumn{2}{c}{ Maneio de solo ${ }^{\underline{1}}$} \\
\cline { 2 - 3 } & Plantio Direto (PD) & Preparo Convencional (PC) \\
\hline Milho para grão (MG) & $2,4289 \mathrm{Ba}$ & $2,6429 \mathrm{Aa}$ \\
Milho para silagem (MS) & $3,6216 \mathrm{Aa}$ & $2,5373 \mathrm{Ab}$ \\
\hline
\end{tabular}

${ }^{1}$ As médias seguidas de pelo menos uma mesma letra maiúscula na coluna e minúscula na linha não diferem entre si a $5 \%$ de probabilidade pelo Teste de Tukey.

As plantas daninhas que emergem antes das plântulas de milho, ou simultaneamente a elas, são as mais prejudiciais, sendo que as de emergência tardia, depois da cultura fechar, não influenciam diretamente a produção, mas podem dificultar a colheita e prejudicar a qualidade do grão (Almeida, 1991). Registrou-se, neste trabalho que devido a ocorrência de $S$. niveum Kuntze, na área experimental, tornou-se necessária uma quarta aplicação de herbicida, pois, a ausência de controle desta espécie poderia impedir a colheita do milho, devido ao 
seu hábito de crescimento trepador. Como pode se observar no Quadro 7, não houve diferença entre os tipos de manejo de solo para a ocorrência de $S$. niveum Kuntze no tratamento com milho para grão, mas ocorreu diferença significativa no milho para silagem.

\section{AGRADECIMENTOS}

Ao Departamento de Fitotecnia da Universidade Federal de Viçosa e ao Conselho Nacional de Desenvolvimento Científico e Tecnológico (CNPq), pelo apoio financeiro para realização deste trabalho.

\section{LITERATURA CITADA}

ALMEIDA, F.S. Controle de plantas daninhas em plantio direto. Londrina: IAPAR, 1991. 34 p. (IAPAR. Circular, 67).

BELTRÃO, N.E.M., AZEVÊDO, D.M.P. Controle de plantas daninhas na cultura do algodão. Campina Grande: EMBRAPA-CNPA; Brasília: EMBRAPA-SPI, 1994. $154 \mathrm{p}$.

DEUBER, R. Ciência das Plantas Daninhas: fundamentos. Jaboticabal: FUNEP, 1992. $431 \mathrm{p}$.

FORSTER, R., CERDEIRA, A.L. Multiplicação vegetativa da Tiririca (Cyperus rotundus L.). Jaguariúna: EMBRAPA-CNPDA, 1993.

GAZZIERO, D.L.P., SOUZA, I.F. Manejo integrado de plantas daninhas. In: ARANTES, N.E. e SOUZA, P.I.M. ed. Cultura da soja nos cerrados. Piracicaba: POTAFOS, 1993. p. 183-208.

JORDAN-MOLERO, J.E., STOLLER, J.G. Seasonal development of yellow and purple nutsedges (Cyperus esculentus and Cyperus rotundus). Weed Science, v.26, p.614-618, 1978.

LORENZI, H. Manual de identificação e controle de plantas daninhas: plantio direto e convencional. 5 ed. Nova Odessa: Instituto Plantarum, 2000. 381p.

PATTERSON, D.T. Shading responses of purple and yellow nutsedges (Cyperus esculentus and Cyperus rotundus).Weed Science, v.30, n.1, p.25-29, 1982.

PATTERSON, D.T. Comparative Ecophysiology of weeds and crops. In: DUKE, S.O. ed. Weed Physiology. Second Printing. Boca Raton: CRC Press, 1985. p.101-130.

RODRIGUES, B.N. Utilização de herbicidas em plantio direto. In: FANCELLI, A.L., coord. Atualização em plantio direto. Campinas: Fundação Cargill, 1985. p. 51-85.

RODRIGUES, B.N., ALMEIDA, F.L.S. Guia de herbicidas. 3 ed. Londrina, edição dos autores, 1998. 675p.

SEGUY, L., BOUZINAC, S., MAEDA, N. et al. La maîtrese de Cyperus rotundus par le semis direct em culture cotonnière au Brésil. Agriculture et développement, n.21, p. 87-97, 1999.

VOLL, E. Manejo da resteva, do preparo do solo e de herbicidas no controle de plantas daninhas. Plantio Direto, Ponta Grossa, ano V, n. 22, EMBRAPA/Fundação ABC/IAPAR/EMATER, 1987. p.8. 